\title{
The Classification of Sini Decoction Pattern in Traditional Chinese Medicine by Gene Expression Profiling
}

\author{
Hung-Tsu Cheng, ${ }^{1,2}$ Chaang-Ray Chen, ${ }^{3}$ Chia-Yang Li, ${ }^{4}$ Chao-Ying Huang, ${ }^{3}$ \\ Wun-Yi Shu, ${ }^{5}$ and Ian C. Hsu ${ }^{3}$ \\ ${ }^{1}$ Institute of Nano Engineering and Microsystems, National Tsing Hua University, No. 101, Section 2, \\ Kuang-Fu Road, Hsinchu 300, Taiwan \\ ${ }^{2}$ Classics Chinese Medicine Clinic, Taipei 104, Taiwan \\ ${ }^{3}$ Department of Biomedical Engineering and Environmental Sciences, National Tsing Hua University, Hsinchu 300, Taiwan \\ ${ }^{4}$ Department of Genome Medicine, College of Medicine and Center for Infectious Disease and Cancer Research, \\ Kaohsiung Medical University, Kaohsiung 807, Taiwan \\ ${ }^{5}$ Institute of Statistics, National Tsing Hua University, Hsinchu 300, Taiwan
}

Correspondence should be addressed to Ian C. Hsu; ichsu@mx.nthu.edu.tw

Received 18 November 2015; Revised 21 February 2016; Accepted 10 March 2016

Academic Editor: Kamal D. Moudgil

Copyright (C) 2016 Hung-Tsu Cheng et al. This is an open access article distributed under the Creative Commons Attribution License, which permits unrestricted use, distribution, and reproduction in any medium, provided the original work is properly cited.

\begin{abstract}
We investigated the syndromes of the Sini decoction pattern (SDP), a common ZHENG in traditional Chinese medicine (TCM). The syndromes of SDP were correlated with various severe Yang deficiency related symptoms. To obtain a common profile for SDP, we distributed questionnaires to 300 senior clinical TCM practitioners. According to the survey, we concluded 2 sets of symptoms for SDP: (1) pulse feels deep or faint and (2) reversal cold of the extremities. Twenty-four individuals from Taipei City Hospital, Linsen Chinese Medicine Branch, Taiwan, were recruited. We extracted the total mRNA of peripheral blood mononuclear cells from the 24 individuals for microarray experiments. Twelve individuals (including 6 SDP patients and 6 non-SDP individuals) were used as the training set to identify biomarkers for distinguishing the SDP and non-SDP groups. The remaining 12 individuals were used as the test set. The test results indicated that the gene expression profiles of the identified biomarkers could effectively distinguish the 2 groups by adopting a hierarchical clustering algorithm. Our results suggest the feasibility of using the identified biomarkers in facilitating the diagnosis of TCM ZHENGs. Furthermore, the gene expression profiles of biomarker genes could provide a molecular explanation corresponding to the ZHENG of TCM.
\end{abstract}

\section{Introduction}

Traditional Chinese medicine (TCM) has been adopted to treat the Chinese for thousands of years on the basis of some classic Chinese medicine textbooks, including Huang Ti Nei Jing ("The Inner Cannon of Huangti") [1], Shénnóng Bèn Căo Jing [2], and Shang Han Za Bing Lun ("Treatise on Cold Damage Disorders") [3]. Shang Han Za Bing Lun is a Chinese medical treatise written by Zhang Zhongjing

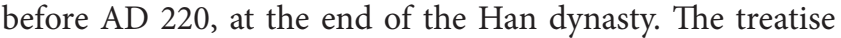
is the oldest comprehensive clinical textbook in the world containing principles, methods, formulas, and medicine and is the clinical literature of TCM theory with practice. To obtain the appropriate decoction for a particular ZHENG requires a diagnostic system, namely, the Decoction ZHENG proposed in Shang Han Za Bing Lun. Through the methods of inspection, listening, smelling, inquiry, and palpation, physicians collect information on patients to identify their TCM ZHENGs according to their personal experience and then treat these patients with herbs, which is called decoction. The methods applied in TCM have been criticized as insufficiently scientific. To overcome this weakness, we conducted systems biology research to differentiate TCM ZHENGs.

Systems biology-based diagnostic principles can be used to support the relationship between TCM and current biomedicine $[4,5]$. From the perspective of gene expression 
profile, TCM ZHENGs differentiation is closely related to gene polymorphisms and differences in gene expression profile. Therefore, applying advanced sequencing techniques and cDNA microarray studies can help to clarify the biological basis of TCM ZHENGs [4]. For example, by using microarray, real-time polymerase chain reaction, and enzyme-linked immunosorbent assay technologies, Shen Yang Xu ZHENG has been determined to be involved with the gene level [6] and may be primarily attributed to the insufficient activity of the mitogen-activated protein kinase (MAPK) pathway [7]. The cold ZHENG was discovered to be possibly caused by a physiological imbalance and disorder of metabolite processes by using microarray technology [8]. Human mRNAs in peripheral blood mononuclear cells (PBMCs) were extracted for microarray experiments to analyze differently expressed gene expressions for TCM cold and hot ZHENG differentiation [9-11].

In this study, we investigated the syndromes of Sini decoction pattern (SDP). Sini decoction was first mentioned in Shang Han Za Bing Lun Sini decoction consisting of three herbs: fresh Aconitum carmichaelii, dry Zingiber officinale, and Glycyrrhiza uralensis, which was characterized as a remedy to have essential effect of recuperating the patients from collapse. It was used to treat the syndrome of displaying coldness on the extremities, pulse feels deep or faint, continuous diarrhea with undigested cereal, profuse perspiration, abdominal fullness and distention, vomiting, and lethargy [12]. Based on the clinical applications of Sini decoction, SDP was then developed by Sun [13]. The syndromes of SDP were correlated with numerous symptoms, such as a slow pulse, coldness on the extremities, continuous diarrhea with undigested cereal, and severe diarrhea, but no common profile exists. According to our survey of 300 senior clinical TCM practitioners, we obtained a common profile for SDP: (1) pulse feels deep or faint and (2) reversal cold of the extremities. We collected SDP patients with these 2 symptoms. In this study, 12 patients with SDP and 12 non-SDP individuals were recruited from Taipei City Hospital, Linsen Chinese Medicine Branch, Taiwan.

We extracted the total mRNA of PBMCs from the 24 individuals for microarray experiments. Twelve individuals (including 6 SDP patients and 6 non-SDP individuals) were used as the training set to identify the biomarkers that were screened using the hypothesis test for distinguishing the SDP and non-SDP groups. The remaining 12 individuals (including 6 SDP patients and 6 non-SDP individuals) were used as the test set to examine whether the identified biomarkers can distinguish the SDP and non-SDP groups. The test results indicated that the gene expression profiling by the biomarkers could effectively distinguish the 2 groups by using a hierarchical clustering algorithm.

Our results suggested the feasibility of using biomarkers extracted from the gene expressions of PBMCs in facilitating the diagnosis of TCM ZHENGs. Furthermore, the gene expression profiles of biomarkers could provide the possible molecular mechanisms of related TCM ZHENGs.

\section{Materials and Methods}

2.1. Chinese Medicine Terminology. All Chinese medicine terms used in this paper were in accordance with the International Acupuncture Nomenclature (IAN) proposed by WHO in 1991; if not available in IAN, the standard nomenclature proposed in the WHO International Standard Terminologies on Traditional Medicine in the Western Pacific Region [14] was adapted. These translated Chinese medicine terms are presented in italics in this paper.

2.2. Human Participants. The syndromes of SDP were associated with a slow, deep, and faint pulse that disappeared, coldness on the extremities, severe diarrhea, continuous diarrhea with undigested cereal, generalized pain, abdominal fullness, cold-fluid retention on the diaphragm, profuse sweating, severe spasms in the feet, tight clamping of the extremities, and reversal cold in both the hands and feet; however, no common profile exists. To obtain a common profile for SDP, we distributed questionnaires to 300 senior clinical TCM practitioners. Our questionnaire listed 41 symptoms related to SDP. In the survey, each senior clinical TCM practitioner assigned a score to each symptom, indicating the correlation between the symptom and SDP from high to low $(5,4,3,2,1$, and 0 ). We identified symptoms that collectively constituted a common SDP profile according to the frequency with which participating TCM practitioners assigned a score of 5 to the symptoms; the frequency threshold was set at higher than $35 \%$ of the returned surveys. We recruited SDP patients with the aforementioned symptoms. In this study, 12 SDP patients and 12 non-SDP individuals from Taipei City Hospital, Linsen Chinese Medicine Branch, Taiwan, were recruited. All of the individuals provided informed consent. The definition of healthy subject was diagnosed by western medicine rather different from TCM. It is difficult to diagnose healthy subject. Therefore, we consider substituting non-SDP patients for healthy subject. We try our best to collect non-SDP patients who are alike healthy subjects.

2.3. Blood Sample Collection. We phlebotomized $30 \mathrm{~mL}$ of human peripheral blood from each donor and then separated the blood into three $10 \mathrm{~mL}$ plastic whole blood tubes with spray-coated K2EDTA (Becton Dickenson, Franklin Lakes, NJ, USA). The blood was transferred to a $50 \mathrm{~mL}$ centrifuge tube. The PBMCs were then prepared from the $30 \mathrm{~mL}$ of peripheral blood through Ficoll-Hypaque density gradient centrifugation. The PBMCs were added to an RNAlater RNA Stabilization Reagent (Qiagen, Valencia, CA, USA) and then placed into a bottle with liquid nitrogen. All of these procedures were performed immediately after the blood was collected at the laboratory of Taipei City Hospital, Linsen Chinese Medicine Branch, Taiwan. The isolated PBMCs were frozen, stored in a liquid nitrogen freezer, and transported to the microarray experimental laboratory at National Tsing Hua University, Hsinchu, Taiwan, for further microarray experiments.

2.4. RNA Extraction and Microarray Hybridization. We extracted total RNA by using the RNeasy Mini Kit according 
to the manufacturer's protocol (Qiagen, Valencia, CA, USA). Total RNA quantity and quality were assessed using an ultraviolet absorption spectrophotometer at 260 and $280 \mathrm{~nm}$. Subsequently, $\alpha$ - and $\beta$-globin mRNA were reduced from a portion of the total RNA samples by using the GLOBINclear $^{\mathrm{TM}}$ human kit (Ambion, Austin, TX, USA), according to the manufacturer's instructions, at the recommended start quantity of $10 \mu \mathrm{g}$ of total RNA. The quality of total RNA was evaluated using the Agilent 2100 bioanalyzer with the RNA 6000 Nano LabChip kit (Agilent Technologies, Palo Alto, CA, USA). Before reverse transcription, each RNA sample was spiked with a mixture of Arabidopsis mRNAs, which we called doping control. Fluorescence-labeled (Cy3, Cy5-3DNA Capture Reagent) cDNA was conducted using the 3DNA Array 900 labeling kit according to the manufacturer's protocols (Genisphere, Hatfield, PA, USA). Reverse transcription was performed using SuperScript II (Invitrogen, Carlsbad, CA, USA). Hybridization was performed at $65^{\circ} \mathrm{C}$ in a water bath for 16 to $18 \mathrm{~h}$, and arrays were washed according to the manufacturer's protocol (Corning Life Sciences, New York, NY, USA). The arrays were scanned using GenePix 4000B scanner (Axon Instruments, Foster City, CA, USA).

2.5. Microarray Fabrication. A total of 9600 human cDNA clones were purchased from Incyte Genomics (Wilmington, DE, USA). These cDNAs were randomly selected from the IMAGE library. Resequencing was performed on these clones, and 7334 cDNAs were verified to have corrected DNA sequences. These 7334 sequence-verified human cDNAs (Incyte Genomics) and 10 Arabidopsis cDNAs (SpotReport ${ }^{\mathrm{TM}}$ cDNA Array Validation System; Stratagene, La Jolla, CA, USA), serving as spike-in controls, and one housekeeping gene $(\beta$-actin), serving as a positive control, were arrayed on Corning UltraGAPS slides (Corning, Corning, NY, USA). These 7334 human cDNAs and 96 Arabidopsis cDNAs and housekeeping genes were spotted in quadruplicate on each array making a total of 32248 spots to enhance the statistical confidence in the gene expression data. Each array had 32,448 spots. The arrays were postprocessed according to the Corning UltraGAPS Coated Slides instruction manual.

2.6. Experimental Design. Loop design, a type of statistical microarray experimental design, was adopted to construct an optimal design. The basic principles of optimal design are a balance among the factors, approximately equal sampling of varieties, and minimal distance between pairs of varieties [15]. Samples from 24 individuals were hybridized on 48 arrays based on the 2 loop designs presented in Figure 1. The individuals of samples L1A1, L1A2, L1A3, L1C1, L1C2, L1C3, L2A1, L2A2, L2A3, L2C1, L2C2, and L2C3 were SDP patients, and those of samples L1B1, L1B2, L1B3, L1D1, L1D2, L1D3, L2B1, L2B2, L2B3, L2D1, L2D2, and L2D3 were non-SDP individuals. Each arrow in the figure indicates a microarray hybridization experiment. The arrow heads and tails represent samples labeled with Cy5 (3DNA Capture Reagent) and Cy3 (3DNA Capture Reagent), respectively. The black solid circles stand for the SDP samples and the open circles stand for non-SDP samples. We used 12 individuals in
Loop 1 experiments as the training set and the remaining 12 individuals in Loop 2 experiments as the test set.

2.7. Microarray Data Analysis and Statistical Analysis. Microarray data preprocessing, normalization, and statistical analysis were performed using the bioinformatics software suite Tsing Hua Engine for Microarray Experiment [16].

Spot-screening rules were applied to screen invalid spots on these arrays. The spot-screening rules for the data of Loop 1 (the training set) were as follows: (1) exclude the spots defined as "flag bad" or "absent" in all GenePix Results (GPR), (2) exclude the spots with diameters less than $100 \mu \mathrm{m}$, (3) exclude the spots with a coefficient of variation (CV) of pixel intensity of over $100 \%$ in both channels, and (4) exclude the spots with signal to noise ratios (SNRs) in both channels were less than 2 in the training set microarray experiments. The SNR is defined as $(S-B) / B(S$ : mean of pixel intensities of the signal; $B$ : median pixel intensity of the background). The logarithm of the ratios for all valid spots on each array was normalized using global lowess normalization [17]. After the data were preprocessed, the normalized log ratios of the fluorescence intensity of each cDNA spot were analyzed using a log linear model, which was described in our previous study [18], to obtain the least-squares estimates $\widehat{\lambda_{1}}, \widehat{\lambda_{2}}, \widehat{\lambda_{3}}, \widehat{\lambda_{4}}, \widehat{\lambda_{5}}$, $\widehat{\lambda_{6}}, \widehat{\lambda_{7}}, \widehat{\lambda_{8}}, \widehat{\lambda_{9}}, \widehat{\lambda_{10}}, \widehat{\lambda_{11}}$, and $\widehat{\lambda_{12}}$ for the relative expressions among all of the samples. The relative expressions of sample $i$ are defined as (expression of sample $i$ )/(geometric average of the expression of all samples), for each gene, where $i$ runs from 1 to 12. For the training set microarray data, 4951 genes satisfied the selection criteria of the spot-screening rules and log linear model. The selection criteria for the data of Loop 2 (the test set) are described in the subsequent subsection. The microarray data is available at GEO (GSE67090).

2.8. Searching Biomarkers to Distinguish SDP. We used Loop 1 experiments as the training set and Loop 2 experiments as the test set. For the 4951 genes of Loop 1 (the training set), 192 genes were identified using an $F$ test with null hypothesis $H_{0}$ : $\left(\widehat{\lambda_{1}}+\widehat{\lambda_{3}}+\widehat{\lambda_{5}}+\widehat{\lambda_{7}}+\widehat{\lambda_{9}}+\widehat{\lambda_{11}}\right)-\left(\widehat{\lambda_{2}}+\widehat{\lambda_{4}}+\widehat{\lambda_{6}}+\widehat{\lambda_{8}}+\widehat{\lambda_{10}}+\widehat{\lambda_{12}}\right)=0$, at a Bonferroni-adjusted significance level of $0.05 / 4951$, where $\widehat{\lambda_{1}}, \widehat{\lambda_{3}}, \widehat{\lambda_{5}}, \widehat{\lambda_{7}}, \widehat{\lambda_{9}}$, and $\widehat{\lambda_{11}}$ were the least-squares estimates for the relative expressions of the SDP samples and $\widehat{\lambda}_{2}, \widehat{\lambda_{4}}, \widehat{\lambda_{6}}, \widehat{\lambda_{8}}$, $\widehat{\lambda_{10}}$, and $\widehat{\lambda_{12}}$ were the least-squares estimates for the relative expressions of the non-SDP samples.

The 192 biomarker genes were then used to distinguish the SDP and non-SDP groups of the test set. We applied the selection criteria to filter bad spots to perform an effective normalization and a log linear model. In order to include additional available genes to be tested, we relaxed the selection criteria of the spot-screening rules for the data of Loop 2 (the test set) as follows: (1) exclude the spots defined as "flag bad" or "absent" in all GPR files, (2) exclude the spots with diameters less than $50 \mu \mathrm{m}$, (3) exclude the spots with a CV of pixel standard deviation of over $150 \%$ in both channels, and (4) exclude the spots with SNRs in either channel were less than 1 in the test microarray experiments. The logarithm of the ratios for all valid spots on each array was normalized under the same normalization conditions as those for 


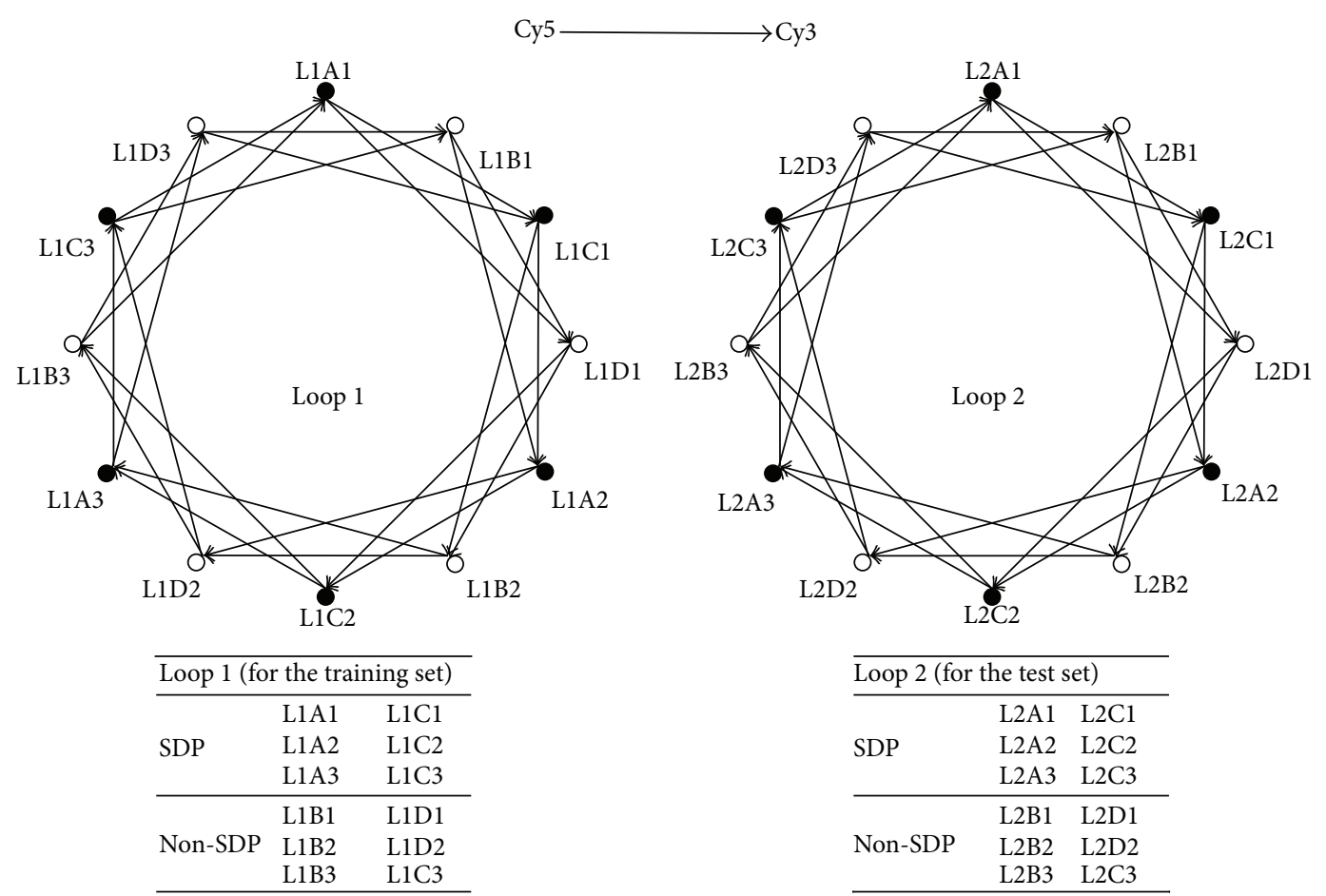

FIGURE 1: Experimental designs of Loop 1 (for the training set) and Loop 2 (for the test set). Each arrow indicates a microarray hybridization experiment. The arrow heads and tails represent samples labeled with Cy5 and Cy3, respectively. The black solid circles stand for the SDP samples and the open circles stand for non-SDP samples. Loop 1 is the experimental design for the training set of 12 individuals. Loop 2 is the experimental design for the test set of the other 12 individuals. The annotations of samples in Loop 1 and Loop 2 are shown below each loop.

the training set. We then used hierarchical clustering to verify whether the gene expression profiles of the 192 biomarker genes could classify the 12 test samples into 2 groups and how well they could distinguish the SDP patients and non-SDP individuals.

2.9. Functional Annotation and Enrichment Analysis. Functional annotation and enrichment analysis were accessed through the database for annotation, visualization, and integrated discovery (DAVID) [19], which performed a modified Fisher's exact test to identify overrepresented functions. DAVID is a widely employed web tool that provides a rapid means to understand the biological meaning of a long list of genes of interest. For any gene list, DAVID can map and convert identifiers (IDs) and accessions among different gene IDs. A long gene list can be reduced into biological themerelated groups of genes, for example, gene ontology (GO) [20] and the Kyoto Encyclopedia of Genes and Genomes (KEGG) pathway [21].

The Entrez gene IDs of 192 biomarker genes were used as the gene ID for bioinformatics analysis. Biological processes of GO terms were used for functional annotation and enrichment analysis of these biomarker genes.

\section{Results}

3.1. Questionnaires to Obtain a Common Profile for SDP. We distributed questionnaires to 300 senior clinical TCM practitioners, and 43 questionnaires were returned. Our questionnaire listed 41 symptoms related to SDP. In the survey, each senior clinical TCM practitioner assigned a score to each symptom, indicating the correlation between the symptom and SDP, from high to low $(5,4,3,2,1$, and 0$)$. Based on the frequency with which participating TCM practitioners assigned a score of 5 to the symptoms, we identified symptoms that collectively constituted a common SDP profile (Figure 2). The frequency threshold was set at higher than $35 \%$ of the 43 returned surveys (i.e., symptoms assigned a score of 5 by at least 16 surveys). This process revealed 7 symptoms to form our symptom profile of SDP patients. By grouping related symptoms, we obtained a common profile for SDP as 2 sets of symptoms: (1) pulse feels deep or faint and (2) reversal cold of the extremities. We recruited SDP patients with the 2 sets of symptoms. In this study, 12 SDP patients and 12 non-SDP individuals were recruited from Taipei City Hospital, Linsen Chinese Medicine Branch, Taiwan. All of the participants provided informed consent.

\subsection{Identifying Biomarker Genes from the Training Set Micro-} array Experiment. On the basis of the results for the 4951 genes of Loop 1 (the training set), 192 genes were identified (Table 1) using an $F$ test with null hypothesis $H_{0}:\left(\widehat{\lambda_{1}}+\widehat{\lambda_{3}}+\right.$ $\left.\widehat{\lambda_{5}}+\widehat{\lambda_{7}}+\widehat{\lambda_{9}}+\widehat{\lambda_{11}}\right)-\left(\widehat{\lambda_{2}}+\widehat{\lambda_{4}}+\widehat{\lambda_{6}}+\widehat{\lambda_{8}}+\widehat{\lambda_{10}}+\widehat{\lambda_{12}}\right)=0$, at a Bonferroni-adjusted significance level of $0.05 / 4951$. By applying hierarchical clustering with Spearman distance and average linkage, the 12 training samples were appropriately separated into 2 groups, as shown in Figure 3. In Figure 3, 
TABLE 1: The 192 biomarker genes identified using an $F$ test with null hypothesis $H_{0}:\left(\widehat{\lambda_{1}}+\widehat{\lambda_{3}}+\widehat{\lambda_{5}}+\widehat{\lambda_{7}}+\widehat{\lambda_{9}}+\widehat{\lambda_{11}}\right)-\left(\widehat{\lambda_{2}}+\widehat{\lambda_{4}}+\widehat{\lambda_{6}}+\widehat{\lambda_{8}}+\widehat{\lambda_{10}}+\widehat{\lambda_{12}}\right)=0$, at a Bonferroni-adjusted significance level of 0.05/4951.

\begin{tabular}{|c|c|c|c|c|}
\hline Gene name & & & & \\
\hline ABHD3 & $\mathrm{ABI} 2$ & ACSM2B & ACTB & AGFG1 \\
\hline AKAP9 & ARG1 & ARID5A & ATP1B3 & ATP6AP2 \\
\hline ATP6V0B & BLZF1 & BPGM & C11orf79 & C12orf24 \\
\hline C12orf32 & C17orf91 & C6orf106 & CAPN1 & CBARA1 \\
\hline CCL18 & CCL5 & CD1D & CD24 & CD40 \\
\hline CD44 & CD83 & CD8A & CD93 & CDC42 \\
\hline CDC42SE2 & CLDN1 & COMT & COX10 & $\mathrm{CP}$ \\
\hline CREM & CST7 & CXCL9 & DEFA1 & DEFA3 \\
\hline DEFA4 & DENND2D & DGCR6L & DLG2 & DUSP6 \\
\hline EEF2 & EIF3E & EIF3I & EPAS1 & EXOSC9 \\
\hline FAM113B & FAM175B & FCER1A & FLNB & FMOD \\
\hline FOLR3 & FOS & FOSB & FYN & GCA \\
\hline GIMAP1 & GLRX & GNG11 & GNG2 & GNLY \\
\hline GPR56 & GSTA2 & GTF2E1 & GZMA & H3F3B \\
\hline HERPUD1 & HIST1H2AC & HIST1H2BD & HIST1H2BG & HIST1H2BJ \\
\hline HIST2H2AA3 & HLA-A & HLA-DMA & HLA-DQB1 & HLA-DRB1 \\
\hline HLA-G & Hs. 282050 & Hs.467411 & Hs. 534061 & Hs. 586682 \\
\hline Hs.591807 & Hs.599359 & Hs. 655903 & Hs. 674438 & Hs. 88605 \\
\hline HSP90B1 & HSPA1A & HTATIP2 & HTR7P1 & ID2 \\
\hline IFIT1 & IL10RA & IL15RA & IL1B & IL32 \\
\hline JARID1C & KIF3C & KLF10 & KLF6 & LCP1 \\
\hline LNP1 & LOC400027 & LOC729776 & LTB & LYRM1 \\
\hline MAPK13 & MBP & MCM3AP & MEST & MLH3 \\
\hline MNDA & MRPL3 & MRPL49 & MTMR6 & MYL6 \\
\hline NCRNA00084 & NHEDC2 & NPY & NUCB1 & NUDT16 \\
\hline NUP93 & ORM1 & PACS1 & PCDH8 & PDE4B \\
\hline PEA15 & PF4 & PLAUR & PNLIPRP2 & POLR1C \\
\hline POLR2D & POU2F2 & РPBP & PPP1R12B & PPP1R7 \\
\hline PPP2R2A & PPRC1 & PPT1 & PRL & PSMC6 \\
\hline RAB4A & RARRES3 & RGS18 & RGS2 & RHOQ \\
\hline RNF40 & RNPEP & RPL41 & RPS11 & RPS24 \\
\hline RPS27 & RPS4X & RPS4Y1 & RUNX3 & S1PR5 \\
\hline SEC22B & SELL & SERPINE2 & SFRS1 & SH2B3 \\
\hline SH3D19 & SHCBP1 & SLC2A3P1 & SOD2 & SPTY2D1 \\
\hline SRGN & STX8 & SYTL2 & TADA3L & TARP \\
\hline THBS1 & TIMP1 & TMEM176A & TNFAIP8L2 & TPCN1 \\
\hline TRA@ & TRAPPC1 & TRMT11 & VIM & VPS13D \\
\hline WDR42A & WIZ & XPNPEP1 & YARS & Unknown* \\
\hline Unknown* & ZNF286A & & & \\
\hline
\end{tabular}

*The sequence of the clone was not yet identified in the BLAST. 


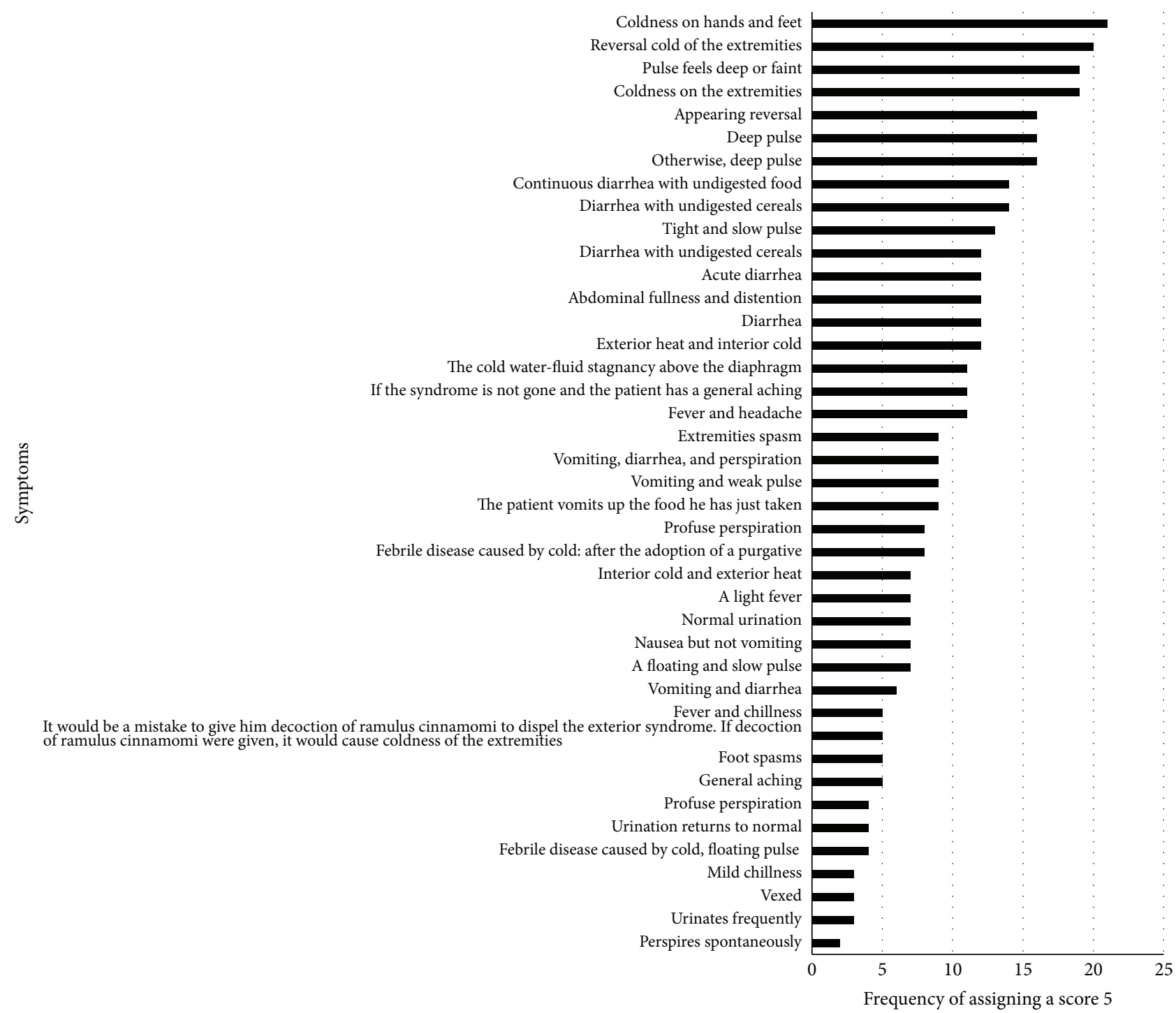

FIGURE 2: Frequency with which survey symptoms were assigned a score of 5 in determining the SDP profile.

the gene expression value used to do the clustering is the relative expressions of the labeled sample.

\subsection{Distinguishing Power of the Biomarker Genes to the Test Set} Microarray Experiment. The 192 biomarker genes identified in the training set experiments were then used to test the ability to distinguish the SDP patients and non-SDP individuals in the test set. To include additional available genes to be tested, we relaxed the selection criteria of the spot-screening rules for the data of the test set (Loop 2). The logarithm of the ratios for all valid spots on each array was normalized under the same normalization conditions as those for the training set. We then used hierarchical clustering to verify whether the gene expression profiles of the 192 biomarker genes could classify the 12 test samples into 2 groups and how well they could distinguish the SDP patients and nonSDP individuals. Under the same clustering conditions (i.e., hierarchical clustering with Spearman distance and average linkage), Figure 4 showed that the 192 biomarker genes can classify the 12 test samples into 2 groups. One group comprised L2A2, L2A1, L2A3, L2C3, L2C2, and L2D1 samples and the other comprised L2D2, L2B3, L2D3, L2B2, L2C1, and L2B1 samples. Except for L2D1 and L2C1 samples, all of the samples were correctly grouped into SDP and non-SDP groups. In Figure 4, the gene expression value used to do the clustering is the relative expressions of the labeled sample. The microarray data of 4 biomarker genes from 7 samples were confirmed by quantitative PCR (qPCR). The correlation coefficients $r$ between microarray data and qPCR for each gene are $0.73,0.83,0.93$, and 0.76 (Appendix A).

\subsection{Functional Annotation and Enrichment Analysis Results} for the 192 Biomarker Genes. The functional annotation and enrichment analysis were accessed using DAVID. Seventyeight GO terms were enriched with a $P$ value less than 0.05 . All enriched GO terms are listed in Appendix B. 78 GO terms 
TABLE 2: The 11 enriched GO terms for 192 biomarker genes (sorted according to $P$ value).

\begin{tabular}{lcrr}
\hline GO term & Description & \# gene & $P$ value \\
\hline GO:0006952 & Defense response & 24 & 0.000000 \\
GO:0006955 & Immune response & 24 & 0.000002 \\
GO:0009617 & Response to bacterium & 11 & 0.000088 \\
GO:0001817 & Regulation of cytokine production & 11 & 0.000172 \\
GO:0048534 & Hemopoietic or lymphoid organ development & 13 & 0.000562 \\
GO:0030097 & Hemopoiesis & 12 & 0.000999 \\
GO:0002520 & Immune system development & 13 & 0.001183 \\
GO:0007610 & Behavior & 14 & 0.004162 \\
GO:0006412 & Translation & 12 & 0.004210 \\
GO:0001775 & Cell activation & 11 & 0.008090 \\
GO:0019725 & Cellular homeostasis & 13 & 0.009574 \\
\hline
\end{tabular}

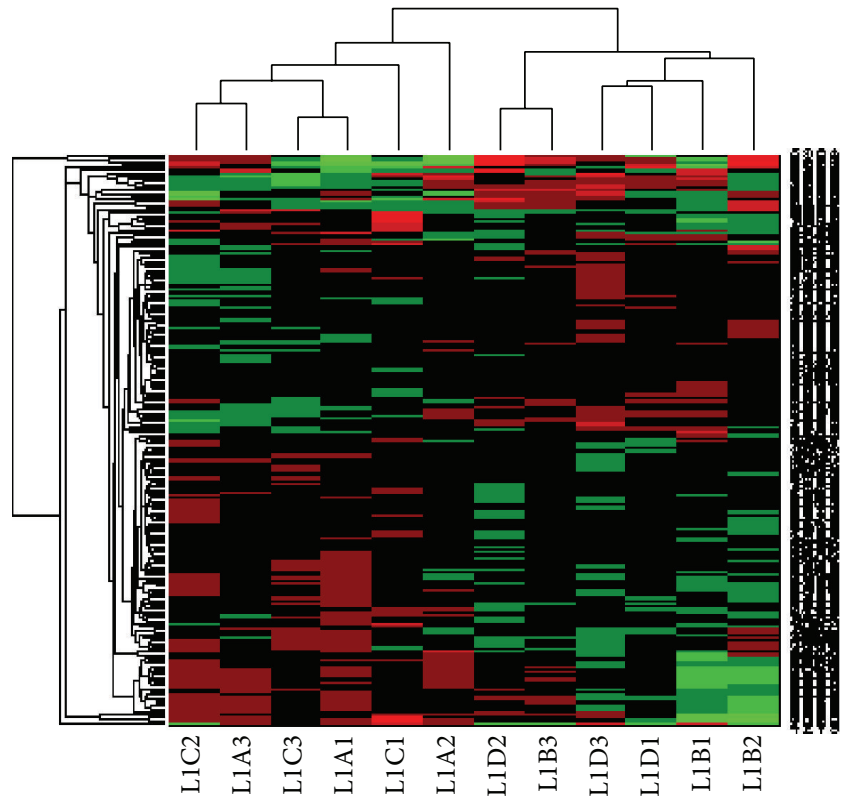

FIgURE 3: 192 genes, identified using the $F$ test at a Bonferroniadjusted significance level of 0.05/4951, were clustered into 2 groups. By applying hierarchical clustering with Spearman distance and average linkage, the 12 training samples were appropriately separated into 2 groups according to the 192 marker genes. Samples L1C2, L1A3, L1C3, L1A1, L1C1, and L1A2 comprised the SDP group, and samples L1D2, L1B3, L1D3, L1D1, L1B1, and L1B2 comprised the nonSDP group. In this figure, the gene expression value used to do the clustering is the relative expressions of the labeled sample.

were enriched with a $P$ value of less than 0.05 . We further applied 2 stringent criteria to filter the high-ranked GO terms: (1) GO terms containing more than 10 genes and (2) a $P$ value of less than 0.01. Consequently, $11 \mathrm{GO}$ terms were identified (Table 2).

Table 2 showed that the 11 GO terms are substantially correlated with immune, inflammation, and hemopoiesis functions. In detail, the immune function includes defense

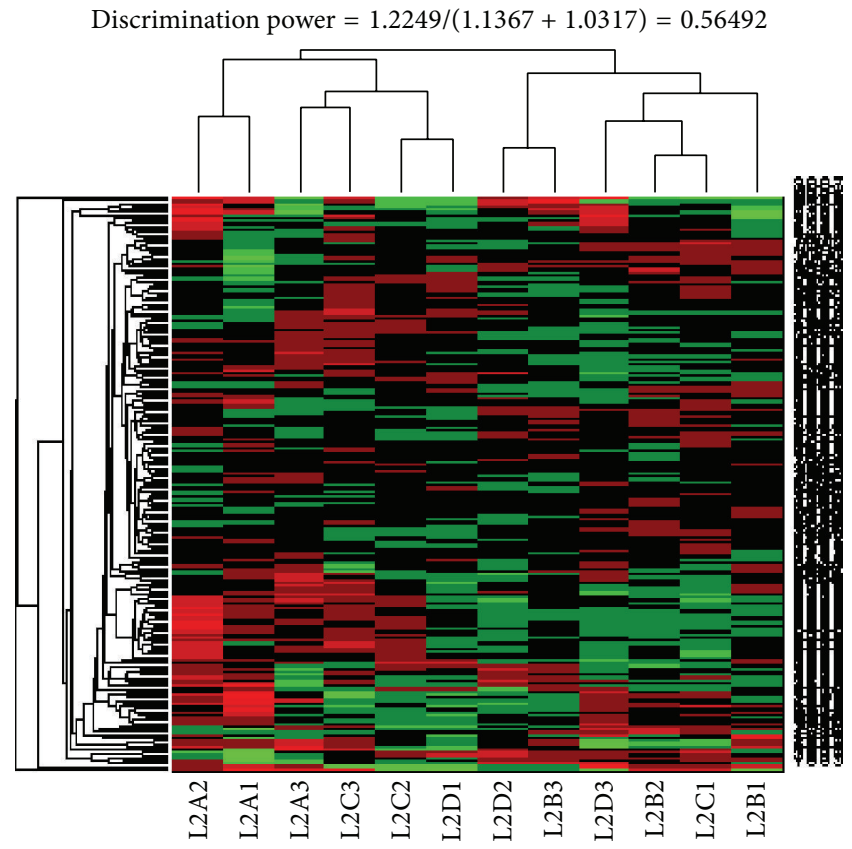

FIGURE 4: Hierarchical clustering results for the 12 test samples. Under the same clustering conditions (i.e., hierarchical clustering with Spearman distance and average linkage), the gene expression profiles of the 192 marker genes classified the 12 test samples into 2 groups. One group consisted of the L2A2, L2A1, L2A3, L2C3, L2C2, and L2D1 samples and the other consisted of the L2D2, L2B3, L2D3, L2B2, L2C1, and L2B1 samples. Except for the L2D1 and L2C1 samples, all of the samples were correctly grouped into SDP and non-SDP groups. In this figure, the gene expression values that used to do the clustering are the relative expressions of the labeled sample.

response, immune response, response to bacterium, and immune system development. The inflammation function includes cytokine production regulation, behavior, cell activation, and cellular homeostasis. The hematopoiesis function includes hemopoietic or lymphoid organ development and hemopoiesis. 
TABLE 3: The correlation plots between microarray data and qPCR data.

\begin{tabular}{|c|c|c|c|c|c|}
\hline \multirow[b]{2}{*}{ Genes } & \multirow[b]{2}{*}{ Samples } & \multicolumn{2}{|c|}{ Microarray data } & \multicolumn{2}{|c|}{ qPCR data } \\
\hline & & $\begin{array}{l}\log _{2} \text { of microarray } \\
\text { relative gene } \\
\text { expression data: } \widehat{\lambda}_{i}\end{array}$ & $\begin{array}{c}\log _{2} \text { ratio of two } \\
\text { samples' microarray } \\
\text { relative gene } \\
\text { expression data: } \\
\widehat{\lambda_{i}}-\widehat{\hat{\lambda}_{j}} \text {, that is, }(a-b)\end{array}$ & $\begin{array}{c}\log _{2} \text { of qPCR relative } \\
\text { gene expression data: } \\
\qquad \Delta \mathrm{Ct}\end{array}$ & $\begin{array}{c}\log _{2} \text { ratio of two } \\
\text { samples' qPCR } \\
\text { relative gene } \\
\text { expression data: } \\
-\Delta \Delta \text { Ct, that is, } \\
-(a-b)\end{array}$ \\
\hline \multirow{7}{*}{ GNG2 } & $\begin{array}{l}\text { (a) L2A1 } \\
\text { (b) L2B2 }\end{array}$ & $\begin{array}{l}0.572 \\
0.097\end{array}$ & 0.476 & $\begin{array}{c}-0.35 \\
0.14\end{array}$ & 0.49 \\
\hline & $\begin{array}{l}\text { (a) } \mathrm{L} 2 \mathrm{~B} 2 \\
\text { (b) } \mathrm{L} 2 \mathrm{~A} 2\end{array}$ & $\begin{array}{l}0.097 \\
0.235\end{array}$ & -0.139 & $\begin{array}{l}0.14 \\
0.80\end{array}$ & 0.66 \\
\hline & $\begin{array}{l}\text { (a) L2A2 } \\
\text { (b) L2D1 }\end{array}$ & $\begin{array}{c}0.235 \\
-0.389\end{array}$ & 0.625 & $\begin{array}{r}0.80 \\
1.75\end{array}$ & 0.95 \\
\hline & $\begin{array}{l}\text { (a) L2D1 } \\
\text { (b) L2C2 }\end{array}$ & $\begin{array}{l}-0.389 \\
-0.222\end{array}$ & -0.167 & $\begin{array}{l}1.75 \\
0.50\end{array}$ & -1.25 \\
\hline & $\begin{array}{l}\text { (a) } \mathrm{L} 2 \mathrm{C} 2 \\
\text { (b) } \mathrm{L} 2 \mathrm{D} 2\end{array}$ & $\begin{array}{l}-0.222 \\
-0.258\end{array}$ & 0.035 & $\begin{array}{r}0.50 \\
1.21\end{array}$ & 0.71 \\
\hline & $\begin{array}{l}\text { (a) L2D2 } \\
\text { (b) L2D3 }\end{array}$ & $\begin{array}{c}-0.258 \\
0.131\end{array}$ & -0.388 & $\begin{array}{l}1.21 \\
0.67\end{array}$ & -0.54 \\
\hline & $\begin{array}{l}\text { (a) L2D3 } \\
\text { (b) L2A1 }\end{array}$ & $\begin{array}{l}0.131 \\
0.572 \\
\end{array}$ & -0.442 & $\begin{array}{c}0.67 \\
-0.35 \\
\end{array}$ & -1.02 \\
\hline \multirow{7}{*}{ RUNX3 } & $\begin{array}{l}\text { (a) L2A1 } \\
\text { (b) L2B2 }\end{array}$ & $\begin{array}{c}0.835 \\
-0.022\end{array}$ & 0.858 & $\begin{array}{l}1.39 \\
2.49\end{array}$ & 1.10 \\
\hline & $\begin{array}{l}\text { (a) L2B2 } \\
\text { (b) } \mathrm{L} 2 \mathrm{~A} 2\end{array}$ & $\begin{array}{l}-0.022 \\
-0.042\end{array}$ & 0.020 & $\begin{array}{l}2.49 \\
2.81\end{array}$ & 0.32 \\
\hline & $\begin{array}{l}\text { (a) L2A2 } \\
\text { (b) L2D1 }\end{array}$ & $\begin{array}{l}-0.042 \\
-0.099\end{array}$ & 0.057 & $\begin{array}{l}2.81 \\
2.85\end{array}$ & 0.04 \\
\hline & $\begin{array}{l}\text { (a) L2D1 } \\
\text { (b) L2C2 }\end{array}$ & $\begin{array}{l}-0.099 \\
-0.258\end{array}$ & 0.159 & $\begin{array}{l}2.85 \\
2.37\end{array}$ & -0.48 \\
\hline & $\begin{array}{l}\text { (a) } \mathrm{L} 2 \mathrm{C} 2 \\
\text { (b) } \mathrm{L} 2 \mathrm{D} 2\end{array}$ & $\begin{array}{l}-0.258 \\
-0.190\end{array}$ & -0.068 & $\begin{array}{l}2.37 \\
2.86\end{array}$ & 0.49 \\
\hline & $\begin{array}{l}\text { (a) } \mathrm{L} 2 \mathrm{D} 2 \\
\text { (b) } \mathrm{L} 2 \mathrm{D} 3\end{array}$ & $\begin{array}{c}-0.190 \\
0.196\end{array}$ & -0.385 & $\begin{array}{l}2.86 \\
2.37\end{array}$ & -0.49 \\
\hline & $\begin{array}{l}\text { (a) L2D3 } \\
\text { (b) L2A1 }\end{array}$ & $\begin{array}{l}0.196 \\
0.835 \\
\end{array}$ & -0.640 & $\begin{array}{l}2.37 \\
1.39 \\
\end{array}$ & -0.98 \\
\hline & $\begin{array}{l}\text { (a) L2A1 } \\
\text { (b) L2B2 }\end{array}$ & $\begin{array}{l}1.301 \\
0.224\end{array}$ & 1.076 & $\begin{array}{l}-1.65 \\
-0.90\end{array}$ & 0.75 \\
\hline & $\begin{array}{l}\text { (a) } \mathrm{L} 2 \mathrm{~B} 2 \\
\text { (b) } \mathrm{L} 2 \mathrm{~A} 2\end{array}$ & $\begin{array}{l}0.224 \\
0.493\end{array}$ & -0.268 & $\begin{array}{l}-0.90 \\
-0.72\end{array}$ & 0.18 \\
\hline & $\begin{array}{l}\text { (a) } \mathrm{L} 2 \mathrm{~A} 2 \\
\text { (b) L2D1 }\end{array}$ & $\begin{array}{c}0.493 \\
-0.454\end{array}$ & 0.946 & $\begin{array}{c}-0.72 \\
0.04\end{array}$ & 0.76 \\
\hline CST7 & $\begin{array}{l}\text { (a) } \mathrm{L} 2 \mathrm{D} 1 \\
\text { (b) } \mathrm{L} 2 \mathrm{C} 2\end{array}$ & $\begin{array}{l}-0.454 \\
-0.414\end{array}$ & -0.039 & $\begin{array}{l}0.04 \\
-0.01\end{array}$ & -0.05 \\
\hline & $\begin{array}{l}\text { (a) } \mathrm{L} 2 \mathrm{C} 2 \\
\text { (b) } \mathrm{L} 2 \mathrm{D} 2\end{array}$ & $\begin{array}{l}-0.414 \\
-0.325\end{array}$ & -0.089 & $\begin{array}{c}-0.01 \\
0.23\end{array}$ & 0.24 \\
\hline & $\begin{array}{l}\text { (a) } \mathrm{L} 2 \mathrm{D} 2 \\
\text { (b) } \mathrm{L} 2 \mathrm{D} 3\end{array}$ & $\begin{array}{c}-0.325 \\
0.300\end{array}$ & -0.626 & $\begin{array}{c}0.23 \\
-0.62\end{array}$ & -0.85 \\
\hline & $\begin{array}{l}\text { (a) } \mathrm{L} 2 \mathrm{D} 3 \\
\text { (b) } \mathrm{L} 2 \mathrm{~A} 1\end{array}$ & $\begin{array}{r}0.300 \\
1.301 \\
\end{array}$ & -1.000 & $\begin{array}{l}-0.62 \\
-1.65\end{array}$ & -1.03 \\
\hline & $\begin{array}{l}\text { (a) L2A1 } \\
\text { (b) L2B2 }\end{array}$ & $\begin{array}{c}-1.136 \\
0.313\end{array}$ & -1.449 & $\begin{array}{l}2.29 \\
0.76\end{array}$ & -1.53 \\
\hline & $\begin{array}{l}\text { (a) L2B2 } \\
\text { (b) L2A2 }\end{array}$ & $\begin{array}{c}0.313 \\
-0.229\end{array}$ & 0.542 & $\begin{array}{l}0.76 \\
1.88\end{array}$ & 1.12 \\
\hline MNDA & $\begin{array}{l}\text { (a) } \mathrm{L} 2 \mathrm{~A} 2 \\
\text { (b) L2D1 }\end{array}$ & $\begin{array}{l}-0.229 \\
-0.185\end{array}$ & -0.044 & $\begin{array}{l}1.88 \\
1.31\end{array}$ & -0.57 \\
\hline
\end{tabular}


TABLe 3: Continued.

\begin{tabular}{|c|c|c|c|c|c|}
\hline \multirow[b]{2}{*}{ Genes } & \multirow[b]{2}{*}{ Samples } & \multicolumn{2}{|c|}{ Microarray data } & \multicolumn{2}{|c|}{ qPCR data } \\
\hline & & $\begin{array}{l}\log _{2} \text { of microarray } \\
\text { relative gene } \\
\text { expression data: } \widehat{\lambda}_{i}\end{array}$ & $\begin{array}{c}\log _{2} \text { ratio of two } \\
\text { samples' microarray } \\
\text { relative gene } \\
\text { expression data: } \\
\widehat{\lambda_{i}}-\widehat{\lambda_{j}} \text {, that is, }(a-b)\end{array}$ & $\begin{array}{c}\log _{2} \text { of qPCR relative } \\
\text { gene expression data: } \\
\Delta \mathrm{Ct}\end{array}$ & $\begin{array}{c}\log _{2} \text { ratio of two } \\
\text { samples' qPCR } \\
\text { relative gene } \\
\text { expression data: } \\
-\Delta \Delta \text { Ct, that is, } \\
-(a-b)\end{array}$ \\
\hline & $\begin{array}{l}\text { (a) L2D1 } \\
\text { (b) L2C2 }\end{array}$ & $\begin{array}{l}-0.185 \\
-0.015\end{array}$ & -0.170 & $\begin{array}{c}1.31 \\
-0.08\end{array}$ & -1.39 \\
\hline & $\begin{array}{l}\text { (a) } \mathrm{L} 2 \mathrm{C} 2 \\
\text { (b) } \mathrm{L} 2 \mathrm{D} 2\end{array}$ & $\begin{array}{c}-0.015 \\
0.349\end{array}$ & -0.365 & $\begin{array}{c}-0.08 \\
0.17\end{array}$ & 0.25 \\
\hline & $\begin{array}{l}\text { (a) } \mathrm{L} 2 \mathrm{D} 2 \\
\text { (b) } \mathrm{L} 2 \mathrm{D} 3\end{array}$ & $\begin{array}{r}0.349 \\
0.357\end{array}$ & -0.008 & $\begin{array}{l}0.17 \\
1.10\end{array}$ & 0.93 \\
\hline & $\begin{array}{l}\text { (a) } \mathrm{L} 2 \mathrm{D} 3 \\
\text { (b) } \mathrm{L} 2 \mathrm{~A} 1\end{array}$ & $\begin{array}{l}0.357 \\
-1.136\end{array}$ & 1.493 & $\begin{array}{l}1.10 \\
2.29\end{array}$ & 1.19 \\
\hline
\end{tabular}

\section{Discussion}

Of the 4951 genes of the training set, 192 genes were identified using an $F$ test with null hypothesis. By applying hierarchical clustering with Spearman distance and average linkage, the 12 training samples were appropriately separated into SDP and non-SDP groups. The 192 biomarker genes were then used to distinguish the SDP patients and non-SDP individuals in the test set. Under the same clustering conditions, the 12 test samples were clustered into 2 groups. One group comprised L2A2, L2A1, L2A3, L2C3, L2C2, and L2D1 samples and the other comprised L2D2, L2B3, L2D3, L2B2, L2C1, and L2B1 samples. Except for L2D1 and L2C1 samples, all of the samples were correctly grouped into the SDP and nonSDP groups. Thus, we reviewed the original information of these 2 samples. L2C1 sample (classified as SDP according to TCM but clustered into the non-SDP group by using biomarkers) had a deep, rough, and rapid pulse and reversal cold of the extremities. Among the symptoms of $\mathrm{L} 2 \mathrm{C} 1$ sample, reversal cold of the extremities matched the selected symptom of SDP; however, a deep, rough, and rapid pulse was inconsistent with a deep or faint pulse, a selected symptom for SDP. L2D1 sample (categorized as non-SDP according to TCM but clustered into the SDP group by using biomarkers) had a deep and tight pulse, which was particularly deep at the guan site (the guan is immediately central to the radial styloid at the wrist, where the tip of the physician's middle finger is placed), and reversal cold of the extremities. Among the symptoms of L2D1 sample, a deep and tight pulse, particularly at the guan site, did not meet the symptom of a deep or faint pulse, and the sample was thus classified as non-SDP according to TCM. However, reversal cold of the extremities matched the selected symptom of SDP. These findings indicate that, in classifying these 2 samples into SDP and non-SDP groups, uncertain areas exist. Nevertheless, determining biomarkers by using the mRNA profiling method can facilitate identifying the SDP group. Therefore, the traditional dialectical method of TCM is quite trustworthy.
The results of the functional annotation and enrichment analysis of 192 biomarker genes revealed that the 11 GO terms were substantially correlated with immune, inflammation, and hemopoiesis functions. Among the symptoms of SDP, a deep or faint pulse implied the insufficiency of $Q i$ (in the field of medicine, $Q i$ refers both to the refined nutritive substance that flows within the human body and to its functional activities). Insufficiency of $Q i$ indicates the body's resistance against disease is weak. Pathogens can invade the human body easily, and viruses and bacteria could then cause inflammation easily.

\section{Conclusion}

Our results provided the biomarker genes of SDP, which was first mentioned in Shang Han Za Bing Lun. The results provide molecular evidence for TCM in the ZHENGs differentiation of SDP. Using mRNA profiling experiments on patients' PBMCs to discover biomarker genes to test an unknown group of individuals can effectively identify a specific ZHENG. We hope that the mRNA profiling method will become a model for TCM physicians in diagnosis and assist TCM practitioners in evaluating the curative effect of the medication.

\section{Appendix}

\section{A.}

The microarray data of 4 biomarker genes from 7 samples were confirmed by quantitative PCR (qPCR). The correlation plots between microarray data and $\mathrm{qPCR}$ data are shown in Table 3. The correlation coefficients $r$ for each gene are 0.73 (GNG2), 0.83 (RUNX3), 0.93 (CST7), and 0.76 (MNDA), shown in Figure 5.

\section{B.}

The complete list of all enriched GO terms for 192 biomarker genes (sorted according to $P$ value) is shown in Table 4 . 
TABLE 4: The complete list of all enriched GO terms for 192 biomarker genes (sorted according to $P$ value).

\begin{tabular}{|c|c|c|c|}
\hline GO term & Description & \# gene & $P$ value \\
\hline GO:0006952 & Defense response & 24 & 0.000000 \\
\hline GO:0006955 & Immune response & 24 & 0.000002 \\
\hline GO:0019882 & Antigen processing and presentation & 7 & 0.000073 \\
\hline GO:0009617 & Response to bacterium & 11 & 0.000088 \\
\hline GO:0006968 & Cellular defense response & 7 & 0.000149 \\
\hline GO:0001817 & Regulation of cytokine production & 11 & 0.000172 \\
\hline GO:0048534 & Hemopoietic or lymphoid organ development & 13 & 0.000562 \\
\hline GO:0030097 & Hemopoiesis & 12 & 0.000999 \\
\hline GO:0002520 & Immune system development & 13 & 0.001183 \\
\hline GO:0002696 & Positive regulation of leukocyte activation & 8 & 0.001499 \\
\hline GO:0001819 & Positive regulation of cytokine production & 7 & 0.001573 \\
\hline GO:0050867 & Positive regulation of cell activation & 8 & 0.002053 \\
\hline GO:0007610 & Behavior & 14 & 0.004162 \\
\hline GO:0002763 & Positive regulation of myeloid leukocyte differentiation & 4 & 0.004167 \\
\hline GO:0006412 & Translation & 12 & 0.004210 \\
\hline GO:0002684 & Positive regulation of immune system process & 10 & 0.006451 \\
\hline GO:0006414 & Translational elongation & 7 & 0.006467 \\
\hline GO:0002822 & $\begin{array}{l}\text { Regulation of adaptive immune response based on somatic recombination of } \\
\text { immune receptors built from immunoglobulin superfamily domains }\end{array}$ & 5 & 0.007075 \\
\hline GO:0048584 & Positive regulation of response to stimulus & 10 & 0.007697 \\
\hline GO:0001775 & Cell activation & 11 & 0.008090 \\
\hline GO:0051240 & Positive regulation of multicellular organism process & 10 & 0.008151 \\
\hline GO:0002819 & Regulation of adaptive immune response & 5 & 0.008161 \\
\hline GO:0030162 & Regulation of proteolysis & 5 & 0.008161 \\
\hline GO:0001818 & Negative regulation of cytokine production & 4 & 0.008578 \\
\hline GO:0002824 & $\begin{array}{l}\text { Positive regulation of adaptive immune response based on somatic recombination } \\
\text { of immune receptors built from immunoglobulin superfamily domains }\end{array}$ & 4 & 0.008578 \\
\hline GO:0002544 & Chronic inflammatory response & 3 & 0.009217 \\
\hline GO:0010829 & Negative regulation of glucose transport & 3 & 0.009217 \\
\hline GO:0050832 & Defense response to fungus & 3 & 0.009217 \\
\hline GO:0051043 & Regulation of membrane protein ectodomain proteolysis & 3 & 0.009217 \\
\hline GO:0002694 & Regulation of leukocyte activation & 8 & 0.009343 \\
\hline GO:0002706 & Regulation of lymphocyte mediated immunity & 5 & 0.009351 \\
\hline GO:0019725 & Cellular homeostasis & 13 & 0.009574 \\
\hline GO:0002821 & Positive regulation of adaptive immune response & 4 & 0.010479 \\
\hline GO:0042742 & Defense response to bacterium & 5 & 0.010649 \\
\hline GO:0042592 & Homeostatic process & 18 & 0.011731 \\
\hline GO:0006873 & Cellular ion homeostasis & 11 & 0.012021 \\
\hline GO:0050865 & Regulation of cell activation & 8 & 0.012239 \\
\hline GO:0009611 & Response to wounding & 15 & 0.012528 \\
\hline GO:0007267 & Cell-cell signaling & 15 & 0.013447 \\
\hline GO:0050778 & Positive regulation of immune response & 7 & 0.013518 \\
\hline GO:0031640 & Killing of cells of another organism & 3 & 0.013542 \\
\hline GO:0055082 & Cellular chemical homeostasis & 11 & 0.013819 \\
\hline GO:0002705 & Positive regulation of leukocyte mediated immunity & 4 & 0.014959 \\
\hline GO:0002708 & Positive regulation of lymphocyte mediated immunity & 4 & 0.014959 \\
\hline GO:0010827 & Regulation of glucose transport & 4 & 0.014959 \\
\hline GO:0034101 & Erythrocyte homeostasis & 5 & 0.015220 \\
\hline
\end{tabular}


TABle 4: Continued.

\begin{tabular}{|c|c|c|c|}
\hline GO term & Description & \# gene & $P$ value \\
\hline GO:0030098 & Lymphocyte differentiation & 6 & 0.016523 \\
\hline GO:0051251 & Positive regulation of lymphocyte activation & 6 & 0.016523 \\
\hline GO:0050801 & Ion homeostasis & 11 & 0.017255 \\
\hline GO:0045639 & Positive regulation of myeloid cell differentiation & 4 & 0.017545 \\
\hline GO:0002703 & Regulation of leukocyte mediated immunity & 5 & 0.018862 \\
\hline GO:0006935 & Chemotaxis & 7 & 0.020473 \\
\hline GO:0042330 & Taxis & 7 & 0.020473 \\
\hline GO:0045765 & Regulation of angiogenesis & 5 & 0.020868 \\
\hline GO:0006954 & Inflammatory response & 10 & 0.021243 \\
\hline GO:0046649 & Lymphocyte activation & 8 & 0.024760 \\
\hline GO:0045321 & Leukocyte activation & 9 & 0.026088 \\
\hline GO:0002761 & Regulation of myeloid leukocyte differentiation & 4 & 0.026706 \\
\hline GO:0050870 & Positive regulation of $\mathrm{T}$ cell activation & 5 & 0.030175 \\
\hline GO:0048872 & Homeostasis of number of cells & 6 & 0.030221 \\
\hline GO:0009620 & Response to fungus & 3 & 0.030551 \\
\hline GO:0032655 & Regulation of interleukin-12 production & 3 & 0.030551 \\
\hline GO:0031349 & Positive regulation of defense response & 5 & 0.032829 \\
\hline GO:0002699 & Positive regulation of immune effectors process & 4 & 0.033982 \\
\hline GO:0032103 & Positive regulation of response to external stimulus & 5 & 0.035615 \\
\hline GO:0048878 & Chemical homeostasis & 12 & 0.036704 \\
\hline GO:0002504 & $\begin{array}{l}\text { Antigen processing and presentation of peptide or polysaccharide antigen via MHC } \\
\text { class II }\end{array}$ & 3 & 0.037413 \\
\hline GO:0016525 & Negative regulation of angiogenesis & 3 & 0.037413 \\
\hline GO:0050850 & Positive regulation of calcium-mediated signaling & 3 & 0.037413 \\
\hline GO:0006928 & Cell motion & 13 & 0.037784 \\
\hline GO:0006334 & Nucleosome assembly & 4 & 0.037967 \\
\hline GO:0031497 & Chromatin assembly & 4 & 0.037967 \\
\hline GO:0048002 & Antigen processing and presentation of peptide antigen & 3 & 0.044801 \\
\hline GO:0010033 & Response to organic substance & 18 & 0.044896 \\
\hline GO:0030218 & Erythrocyte differentiation & 4 & 0.046616 \\
\hline GO:0065004 & Protein-DNA complex assembly & 4 & 0.046616 \\
\hline GO:0002521 & Leukocyte differentiation & 6 & 0.046793 \\
\hline GO:0014070 & Response to organic cyclic substance & 6 & 0.049526 \\
\hline GO:0002237 & Response to molecule of bacterial origin & 5 & 0.051544 \\
\hline GO:0007626 & Locomotory behavior & 8 & 0.052288 \\
\hline GO:0055080 & Cation homeostasis & 8 & 0.052288 \\
\hline GO:0050848 & Regulation of calcium-mediated signaling & 3 & 0.052676 \\
\hline GO:0051249 & Regulation of lymphocyte activation & 6 & 0.055270 \\
\hline GO:0034728 & Nucleosome organization & 4 & 0.056149 \\
\hline GO:0045619 & Regulation of lymphocyte differentiation & 4 & 0.056149 \\
\hline GO:0002697 & Regulation of immune effectors process & 5 & 0.058846 \\
\hline GO:0002712 & Regulation of B cell mediated immunity & 3 & 0.060999 \\
\hline GO:0002889 & Regulation of immunoglobulin mediated immune response & 3 & 0.060999 \\
\hline GO:0051235 & Maintenance of location & 4 & 0.061237 \\
\hline GO:0032914 & Positive regulation of transforming growth factor-beta 1 production & 2 & 0.061881 \\
\hline GO:0045651 & Positive regulation of macrophage differentiation & 2 & 0.061881 \\
\hline GO:0007611 & Learning or memory & 5 & 0.062693 \\
\hline GO:0008285 & Negative regulation of cell proliferation & 10 & 0.063328 \\
\hline
\end{tabular}


TABle 4: Continued.

\begin{tabular}{|c|c|c|c|}
\hline GO term & Description & \# gene & $P$ value \\
\hline GO:0051241 & Negative regulation of multicellular organism process & 6 & 0.064581 \\
\hline GO:0051789 & Response to protein stimulus & 5 & 0.066670 \\
\hline GO:0016192 & Vesicle-mediated transport & 13 & 0.067653 \\
\hline GO:0042060 & Wound healing & 7 & 0.068209 \\
\hline GO:0001906 & Cell killing & 3 & 0.069736 \\
\hline GO:0046635 & Positive regulation of alpha-beta $\mathrm{T}$ cell activation & 3 & 0.069736 \\
\hline GO:0051094 & Positive regulation of developmental process & 9 & 0.072195 \\
\hline GO:0050863 & Regulation of $\mathrm{T}$ cell activation & 5 & 0.075009 \\
\hline GO:0050900 & Leukocyte migration & 4 & 0.077725 \\
\hline GO:0009895 & Negative regulation of catabolic process & 3 & 0.078852 \\
\hline GO:0046634 & Regulation of alpha-beta $\mathrm{T}$ cell activation & 3 & 0.078852 \\
\hline GO:0030099 & Myeloid cell differentiation & 5 & 0.079368 \\
\hline GO:0055066 & Di-, tri-valent inorganic cation homeostasis & 7 & 0.080251 \\
\hline GO:0006323 & DNA packaging & 4 & 0.083611 \\
\hline GO:0030217 & T cell differentiation & 4 & 0.083611 \\
\hline GO:0043066 & Negative regulation of apoptosis & 10 & 0.085435 \\
\hline GO:0046324 & Regulation of glucose import & 3 & 0.088316 \\
\hline GO:0002863 & Positive regulation of inflammatory response to antigenic stimulus & 2 & 0.091380 \\
\hline GO:0032891 & Negative regulation of organic acid transport & 2 & 0.091380 \\
\hline GO:0032908 & Regulation of transforming growth factor-beta 1 production & 2 & 0.091380 \\
\hline GO:0051918 & Negative regulation of fibrinolysis & 2 & 0.091380 \\
\hline GO:0043069 & Negative regulation of programmed cell death & 10 & 0.092873 \\
\hline GO:0060548 & Negative regulation of cell death & 10 & 0.095435 \\
\hline GO:0045637 & Regulation of myeloid cell differentiation & 4 & 0.095934 \\
\hline GO:0030003 & Cellular cation homeostasis & 7 & 0.096877 \\
\hline GO:0045582 & Positive regulation of $\mathrm{T}$ cell differentiation & 3 & 0.098097 \\
\hline
\end{tabular}
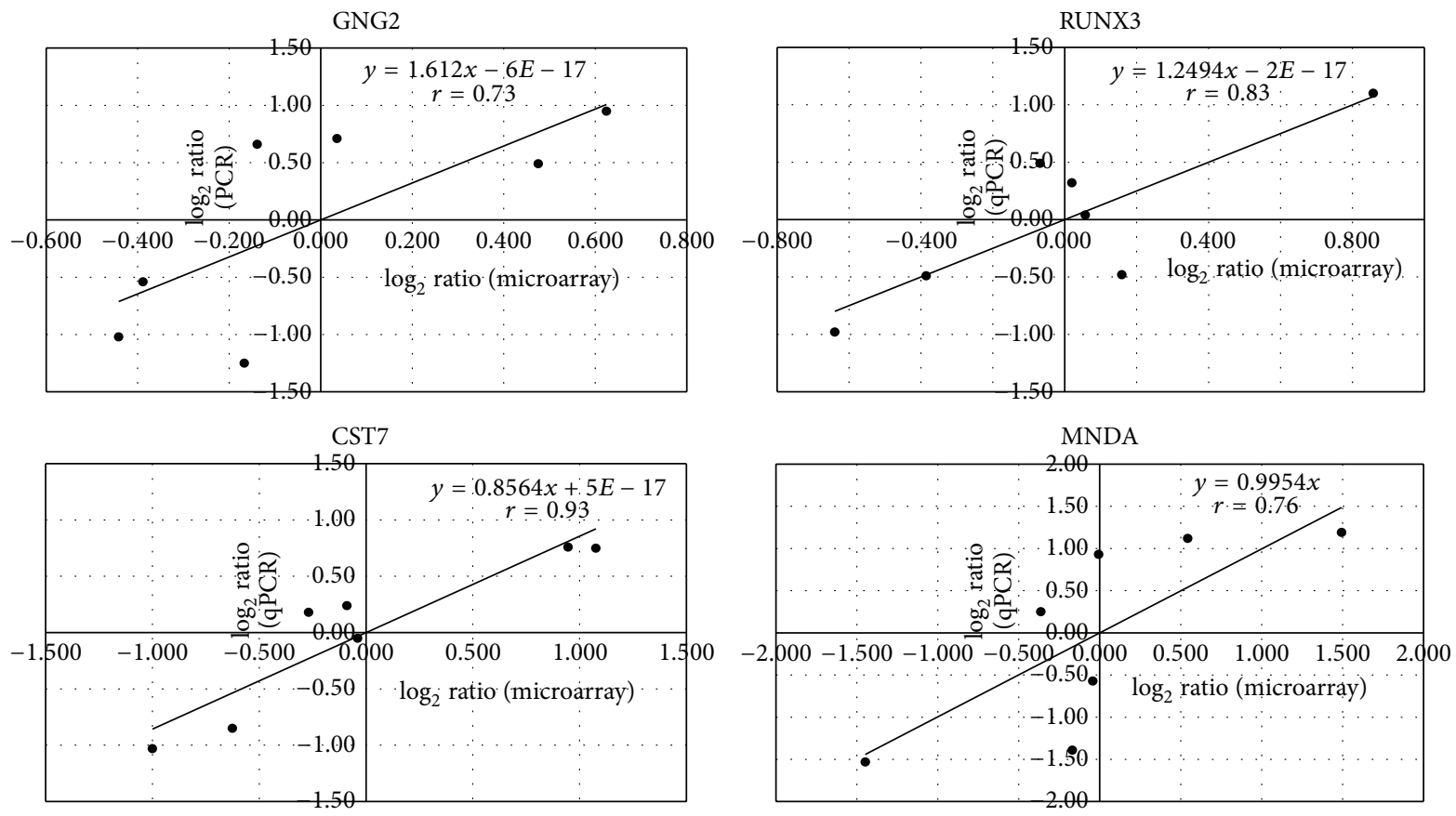

FIGURE 5: The correlation coefficients $r$ for each gene are 0.73 (GNG2), 0.83 (RUNX3), 0.93 (CST7), and 0.76 (MNDA). 


\section{Competing Interests}

The authors declare that they have no competing interests.

\section{References}

[1] P. U. Unschuld, Huang Di Nei Jing Su Wen, University of California Press, Los Angeles, Calif, USA, 2003.

[2] K.-H. Lee, S. Morris-Natschke, X. Yang et al., "Recent progress of research on medicinal mushrooms, foods, and other herbal products used in traditional chinese medicine," Journal of Traditional and Complementary Medicine, vol. 2, no. 2, pp. 8495, 2012.

[3] F. Yu, T. Takahashi, J. Moriya et al., "Traditional Chinese medicine and kampo: a review from the distant past for the future," Journal of International Medical Research, vol. 34, no. 3, pp. 231239, 2006.

[4] M. Xue, H. J. Yin, and K. J. Chen, "Some thoughts on studying essence of syndromes based on genomics," Zhongguo Zhong Xi Yi Jie He Za Zhi, vol. 26, no. 1, pp. 88-90, 2006.

[5] J. van der Greef, H. van Wietmarschen, J. Schroën, M. Wang, T. Hankemeier, and G. W. Xu, "Systems biology-based diagnostic principles as pillars of the bridge between Chinese and Western medicine," Planta Medica, vol. 76, no. 17, pp. 2036-2047, 2010.

[6] W. J. Ding, Y. Z. Zeng, W. H. Li et al., "Identification of linkage disequilibrium SNPs from a kidney-yang deficiency syndrome pedigree," American Journal of Chinese Medicine, vol. 37, no. 3, pp. 427-438, 2009.

[7] W. J. Ding, S. L. Yan, Y. Z. Zeng et al., "Insufficient activity of MAPK pathway is a key monitor of Kidney-Yang Deficiency Syndrome," Journal of Alternative and Complementary Medicine, vol. 15, no. 6, pp. 653-660, 2009.

[8] L. Yang, M. Wang, W. Wu, and L. Zhang, "Transcriptome analysis of cold syndrome using microarray," American Journal of Chinese Medicine, vol. 35, no. 4, pp. 609-620, 2007.

[9] G. Chen, C. Lu, Q. Zha et al., "A network-based analysis of traditional Chinese medicine cold and hot patterns in rheumatoid arthritis," Complementary Therapies in Medicine, vol. 20, no. 1-2, pp. 23-30, 2012.

[10] Q. Pan-Hammarström, S. Wen, and L. Hammarström, "Cytokine gene expression profiles in human lymphocytes induced by a formula of traditional Chinese medicine, vigconic VI-28," Journal of Interferon and Cytokine Research, vol. 26, no. 9, pp. 628-636, 2006.

[11] C. Lu, C. Xiao, G. Chen et al., "Cold and heat pattern of rheumatoid arthritis in traditional Chinese medicine: distinct molecular signatures indentified by microarray expression profiles in CD4-positive T cell," Rheumatology International, vol. 32, no. 1, pp. 61-68, 2012.

[12] J. Liu, K. Peter, D. Shi et al., "Traditional formula, modern application: Chinese medicine formula Sini tang improves early ventricular remodeling and cardiac function after myocardial infarction in rats," Evidence-Based Complementary and Alternative Medicine, vol. 2014, Article ID 141938, 10 pages, 2014.

[13] S. M. Sun, Qian Jin Yi Fang, People's Medical Publishing House, Beijing, China, 1955.

[14] World Health Organization and Regional Office for the Western Pacific, WHO International Standard Terminologies on Traditional Medicine in the Western Pacific Region, World Health Organization Regional Office for the Western Pacific, Manila, Philippines, 2007.
[15] M. K. Kerr and G. A. Churchill, "Experimental design for gene expression microarrays," Biostatistics, vol. 2, no. 2, pp. 183-201, 2001.

[16] C.-R. Chen, W.-Y. Shu, M.-L. Tsai, W.-C. Cheng, and I. C. Hsu, "THEME: a web tool for loop-design microarray data analysis," Computers in Biology and Medicine, vol. 42, no. 2, pp. 228-234, 2012.

[17] J. Schuchhardt, D. Beule, A. Malik et al., "Normalization strategies for cDNA microarrays," Nucleic Acids Research, vol. 28, no. 10, p. E47, 2000.

[18] W.-C. Cheng, W.-Y. Shu, C.-Y. Li et al., "Intra- and interindividual variance of gene expression in clinical studies," PLoS ONE, vol. 7, no. 6, Article ID e38650, 2012.

[19] D. W. da Huang, B. T. Sherman, and R. A. Lempicki, "Bioinformatics enrichment tools: paths toward the comprehensive functional analysis of large gene lists," Nucleic Acids Research, vol. 37, no. 1, pp. 1-13, 2009.

[20] M. Ashburner, C. A. Ball, J. A. Blake et al., "Gene ontology: tool for the unification of biology. The Gene Ontology Consortium," Nature Genetics, vol. 25, no. 1, pp. 25-29, 2000.

[21] M. Kanehisa and S. Goto, "KEGG: kyoto encyclopedia of genes and genomes," Nucleic Acids Research, vol. 28, no. 1, pp. 27-30, 2000 . 


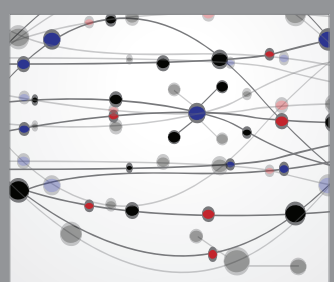

The Scientific World Journal
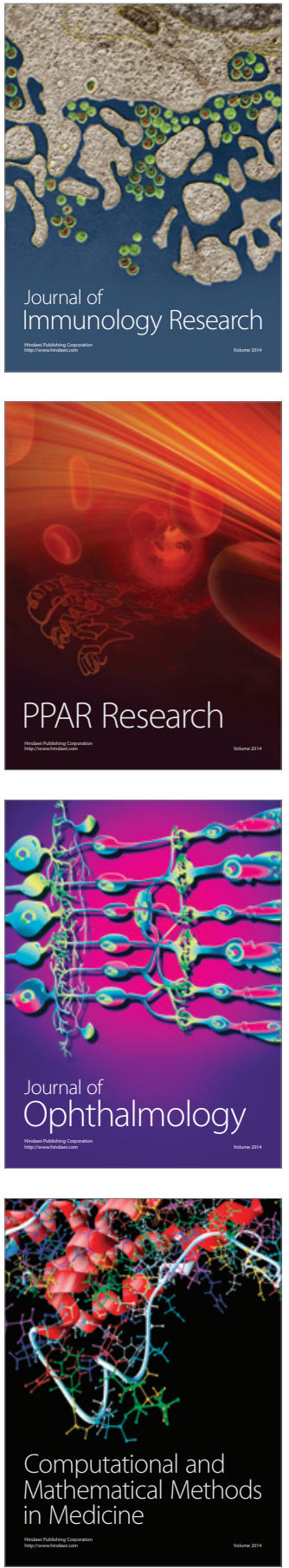

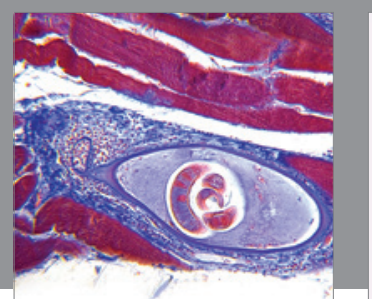

Gastroenterology Research and Practice

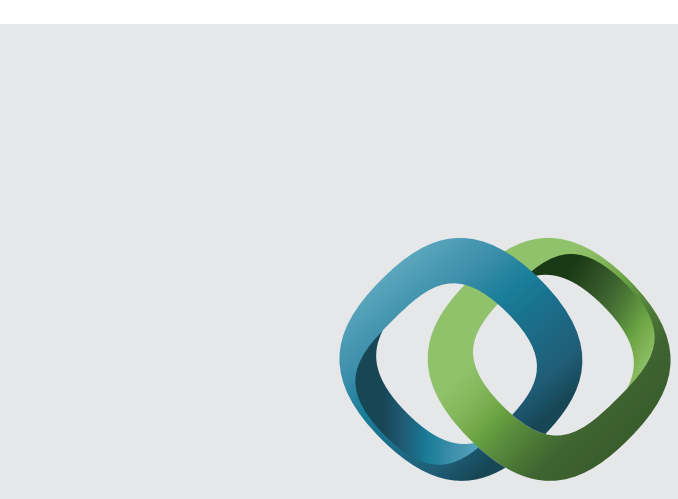

\section{Hindawi}

Submit your manuscripts at

http://www.hindawi.com
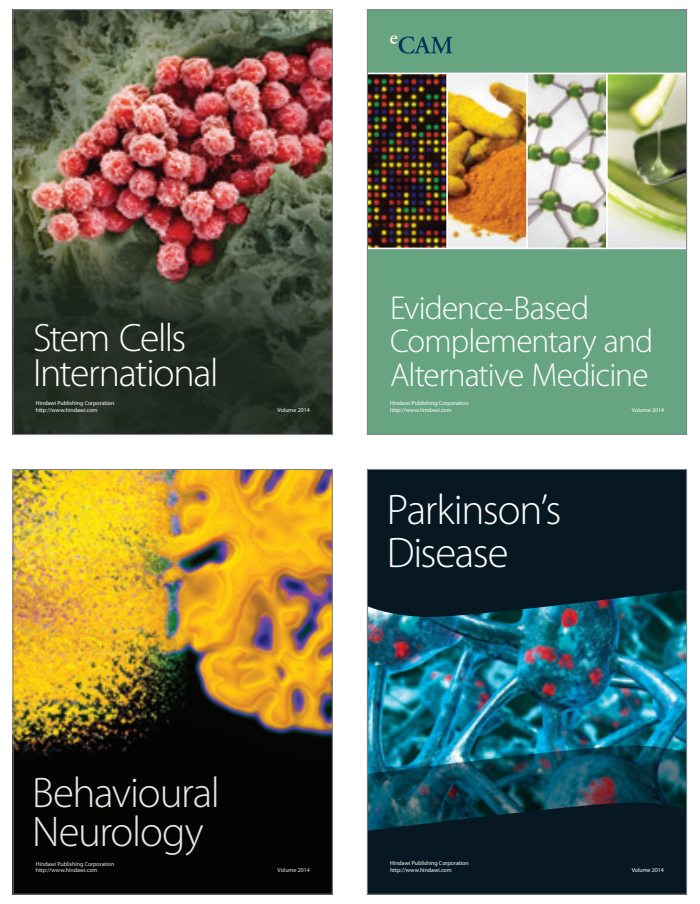
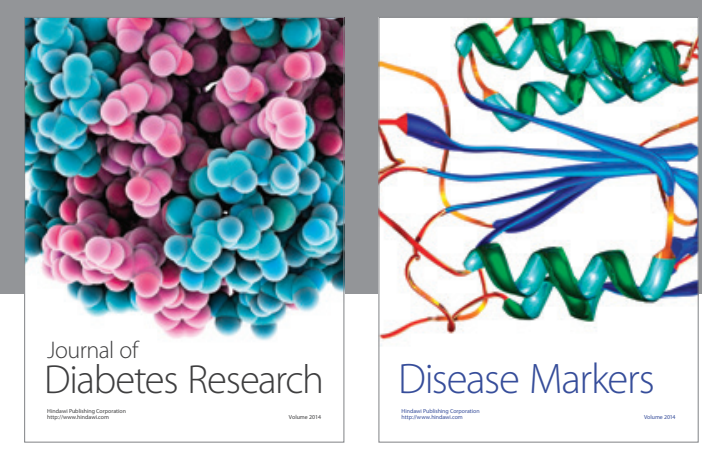

Disease Markers
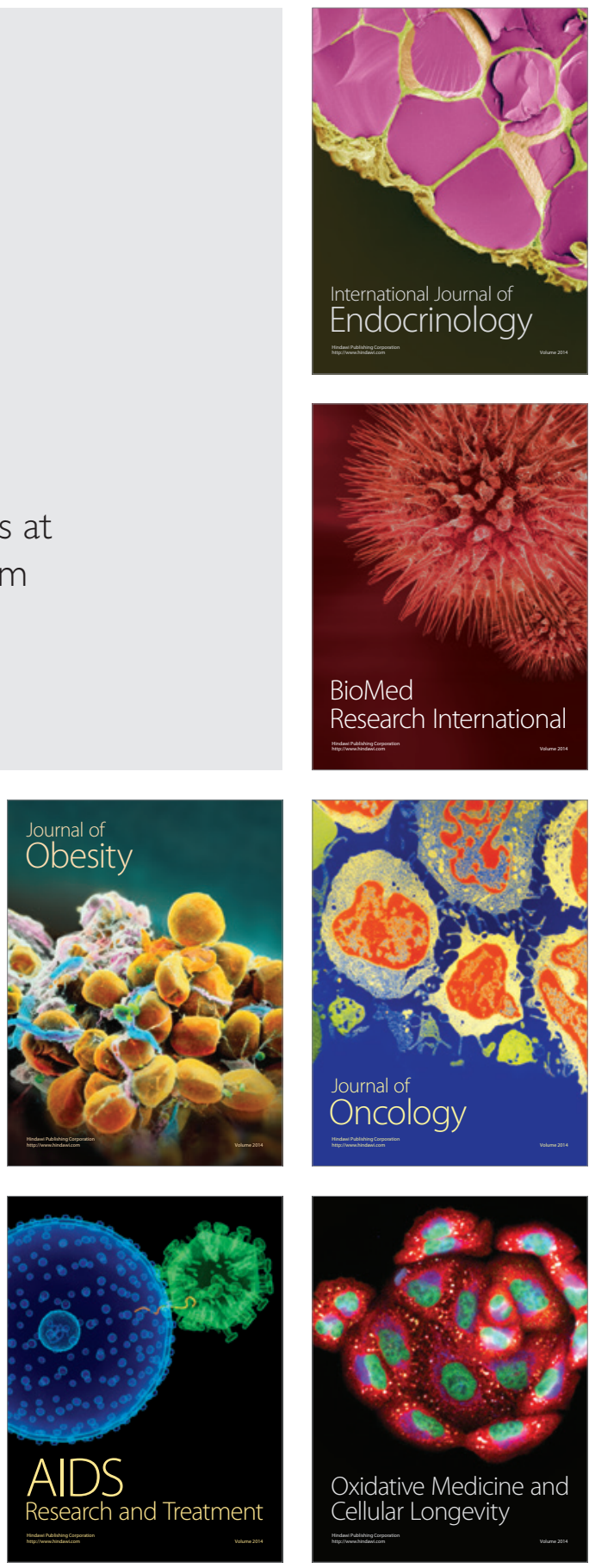